Article

\title{
Superplastic Forming and Reaction Diffusion Bonding Process of Hollow Structural Component for Mg-Gd-Y-Zn-Zr Rare Earth Magnesium Alloy
}

\author{
Peng Peng ${ }^{1,2} \oplus$, Shaosong Jiang ${ }^{1,2, *}$, Zhonghuan Qin $^{3}$ and Zhen Lu ${ }^{1}$ \\ 1 School of Materials Science and Engineering, Harbin Institute of Technology, Harbin 150001, China; \\ ppengwork@163.com (P.P.); luzhenhit@hit.edu.cn (Z.L.) \\ 2 National Key Laboratory for Precision Hot Processing of Metals, Harbin Institute of Technology, \\ Harbin 150001, China \\ 3 Beijing Hangxing Machine Manufacturing Co., Ltd., Beijing 100013, China; qinzhonghuan@126.com \\ * Correspondence: jiangshaosong@hit.edu.cn
}

check for

updates

Citation: Peng, P.; Jiang, S.; Qin, Z.;

Lu, Z. Superplastic Forming and

Reaction Diffusion Bonding Process

of Hollow Structural Component for

Mg-Gd-Y-Zn-Zr Rare Earth

Magnesium Alloy. Metals 2022, 12,

152. https://doi.org/10.3390/

met12010152

Academic Editors: Zhubin He,

Kailun Zheng and Maciej Motyka

Received: 19 December 2021

Accepted: 11 January 2022

Published: 14 January 2022

Publisher's Note: MDPI stays neutral with regard to jurisdictional claims in published maps and institutional affiliations.

Copyright: () 2022 by the authors Licensee MDPI, Basel, Switzerland. This article is an open access article distributed under the terms and conditions of the Creative Commons Attribution (CC BY) license (https:// creativecommons.org/licenses/by/ $4.0 /)$.

\begin{abstract}
This work fabricated a double hollow structural component of Mg-8.3Gd-2.9Y-0.8Zn$0.2 \mathrm{Zr}$ alloy by superplastic forming (SPF) and reaction-diffusion bonding (RDB). The superplastic characteristic and mechanical properties of Mg-8.3Gd-2.9Y-0.8Zn-0.2Zr alloy sheets at $250-450{ }^{\circ} \mathrm{C}$ were studied. Tensile tests showed that the maximum elongation of tensile specimens was about $1276.3 \%$ at $400{ }^{\circ} \mathrm{C}$ under a strain rate of $1 \times 10^{-3} \mathrm{~s}^{-1}$. Besides, the effect of bonding temperature and interface roughness on microstructure and mechanical properties of the reaction diffusion-bonded joints with a $\mathrm{Cu}$ interlayer was investigated. With the increase of temperature, the diffusion coefficient of $\mathrm{Cu}$ increases, and the diffusion transition region becomes wider, leading to tightening bonding of the joint. However, the bonding quality of the joint will deteriorate due to grain size growth at higher temperatures. Shear tests showed that the highest strength of the joints was $152 \mathrm{MPa}$ (joint efficiency $=98.7 \%$ ), which was performed at $460{ }^{\circ} \mathrm{C}$.
\end{abstract}

Keywords: Mg-Re alloys; SPF/RDB; hollow structure; superplastic characteristic; shear strength

\section{Introduction}

Magnesium and its alloys have been widely used in the aerospace, automotive, and $3 \mathrm{C}$ industries (computers, communications, and consumer electronics) due to their excellent physical and chemical properties, such as low density, high specific strength, and stiffness [1-4]. However, their low strength and ductility limit their further application, especially severe strength reduction at high temperatures [5]. Hence, rare earth (RE) magnesium alloys have been paid considerable attention as lightweight structural materials due to their excellent mechanical properties at ambient and elevated temperatures [6].

As a typical lightweight and high strength structure, the multi-layer hollow reinforcement structures can fulfill the requirements in terms of heat dissipation, ventilation, energy absorption, and electromagnetic wave absorption [7-9]. Superplastic forming (SPF) and diffusion bonding (DB) is a technique allowing for processing hollow metallic parts with an internal structure, which traditional machining technologies such as forging, casting, and milling, cannot be used to manufacture [10-13]. As a manufacturing process, SPF exhibits its unique advantages, including greater design freedom, low dies cost, the elimination of spring back, and producing components with complex geometries in one manufacturing step.

In the past few years, many scholars have carried out lots of research on the multilayer hollow reinforcement structural components. Zhang et al. [14] established numerical models of four-layer honeycomb and hollow blade structure of Ti-6Al-4V, and then analyzed the effects of forming parameters (thickness ratio, strain rate, DB distance, and width) on 
groove defect and thickness distribution. Wu et al. [15] studied the superplastic properties of Ti-6Al-4V alloy at elevated temperatures and successfully manufactured a pyramid lattice sandwich panel. Du et al. [16] fabricated a four-layer hollow structural component of TA15 by SPF /DB process at $920{ }^{\circ} \mathrm{C}$ with the target strain rate of $0.001 \mathrm{~s}^{-1}$, and then investigated the microstructure, thickness distribution, and mechanical property of the four-layer hollow structure. In recent years, titanium alloys' SPF/DB technique tends to mature, while the SPF/DB of magnesium alloys is rarely investigated. It is well known that diffusion bonding of magnesium is a formidable challenge because of the compact oxide film covered on the substrate, which acts as a diffusion barrier. Therefore, it is essential to remove or break the continuity of oxide film for realizing diffusion bonding of magnesium alloy during the bonding process. Then $\mathrm{Cu}$ as an interlayer reacting with magnesium to realize diffusion bonding is proposed in this paper.

This study investigated the superplasticity of Mg-8.3Gd-2.9Y-0.8Zn- $0.2 \mathrm{Zr}$ alloy at elevated temperatures. Besides, the effect of bonding temperature and interface roughness on microstructure and mechanical properties of the reaction diffusion-bonded joints with a $\mathrm{Cu}$ interlayer was analyzed. Finally, a double hollow structural component was fabricated by SPF/RDB. The microstructure was characterized, and the thickness distribution of the structure at different regions was measured.

\section{Materials and Methods}

The experimental rare earth (RE) magnesium alloy and the pure $\mathrm{Cu}$ foil $(50 \mu \mathrm{m})$ were provided by Zhengzhou Light Alloy Co. Ltd. (Zhengzhou, China) and Qinghai Haiyuan Aluminum Alloy Co. Ltd. (Qinghai, China). The Mg-RE alloy's composition (in wt $\%$ ) received in forging state was $8.3 \mathrm{Gd}, 2.9 \mathrm{Y}, 0.8 \mathrm{Zn}, 0.2 \mathrm{Zr}$, and the balance $\mathrm{Mg}$.

The tensile specimens with a gauge length of $20 \mathrm{~mm}$, a gauge width of $4.5 \mathrm{~mm}$, and a thickness of $2 \mathrm{~mm}$ were cut from the center of the forged billet using electrical discharge machining. Tensile tests are performed on the Shimadzu AG-Xplus $100 \mathrm{KN}$ testing machine (Shimadzu, Tokyo, Japan) at the temperature ranging from $250{ }^{\circ} \mathrm{C}$ to $450{ }^{\circ} \mathrm{C}$ and the strain rate from $5 \times 10^{-4} \mathrm{~s}^{-1}$ to $1 \times 10^{-2} \mathrm{~s}^{-1}$.

The contact surfaces of Mg-RE alloys were burnished with 180-grit, 800-grit, 1500-grit $\mathrm{SiC}$ paper before bonding, respectively. Subsequently, the polished Mg-RE alloys and the $\mathrm{Cu}$ foil were ultrasonically cleaned in acetone solution, and these cleaned samples were vacuum-sealed until further use. Before welding, the prepared specimens with different sizes (one is L70 $\mathrm{mm} \times \mathrm{W} 10 \mathrm{~mm} \times \mathrm{H} 6 \mathrm{~mm}$, the other is $\mathrm{L} 70 \mathrm{~mm} \times \mathrm{W} 30 \mathrm{~mm} \times \mathrm{H} 6 \mathrm{~mm}$ ) were assembled into a sandwich-type structure with the $\mathrm{Cu}$ interlayer (L70 $\mathrm{mm} \times \mathrm{W} 15 \mathrm{~mm}$ $\times \mathrm{H} 50 \mu \mathrm{m}$ ) in the middle of them, as illustrated in Figure 1a. The diffusion bonding was carried out in a vacuum hot-pressing sintering furnace (Jinzhou Hangxing Vacuum Equipment Co., LTD, Jinzhou, China) (ZRY55, maximum working temperature $=2000^{\circ} \mathrm{C}$, and the ultimate vacuum is $6.7 \times 10^{-3} \mathrm{~Pa}$ ) at $2 \mathrm{MPa}$. In view of the eutectic temperature of the $\mathrm{Mg}$-Cu alloy being $485^{\circ} \mathrm{C}$, the samples were bonded at temperatures of $440{ }^{\circ} \mathrm{C}$, $460{ }^{\circ} \mathrm{C}$, and $480^{\circ} \mathrm{C}$ for $30 \mathrm{~min}$ at an induction heating rate of $20^{\circ} \mathrm{C} / \mathrm{min}$. After the heating preservation, the uniaxial pressure was removed, and the specimens were cooled to ambient temperature in the furnace. The main diffusion bonding parameters are listed in Table 1.

The bonding joints were cut longitudinally, mechanical grinding, polished and finally etched in a glacial acetic acid $(1.7 \mathrm{~mL})$-picric acid $(1.8 \mathrm{~g})$-distilled water $(3 \mathrm{~mL})$-ethyl alcohol $(30 \mathrm{~mL})$ solution for $20 \mathrm{~s}$. The microstructure and microchemical analysis of the joints were performed by scanning electron microscopy (SEM, Quanta 200FEG, FEI company, Hillsboro, OR, USA) in conjunction with energy-dispersive X-ray spectroscopy (EDS) and FEI TALOS F200X scanning transmission electron microscopy (STEM) (FEI company, Hillsboro, OR, USA) coupled with a high-angle annular dark field (HAADF) detector and energy dispersive X-ray spectroscopy. The Instron-5500R testing machine Instron Corporation, Norwood, MA, USA) carried out the shear strength tests at ambient temperature with an initial strain rate of $1 \mathrm{~mm} / \mathrm{min}$. Figure $1 \mathrm{~b}$ shows the schematic 
diagram of the shear test. All the specimens were tested at least three times to avoid random errors.

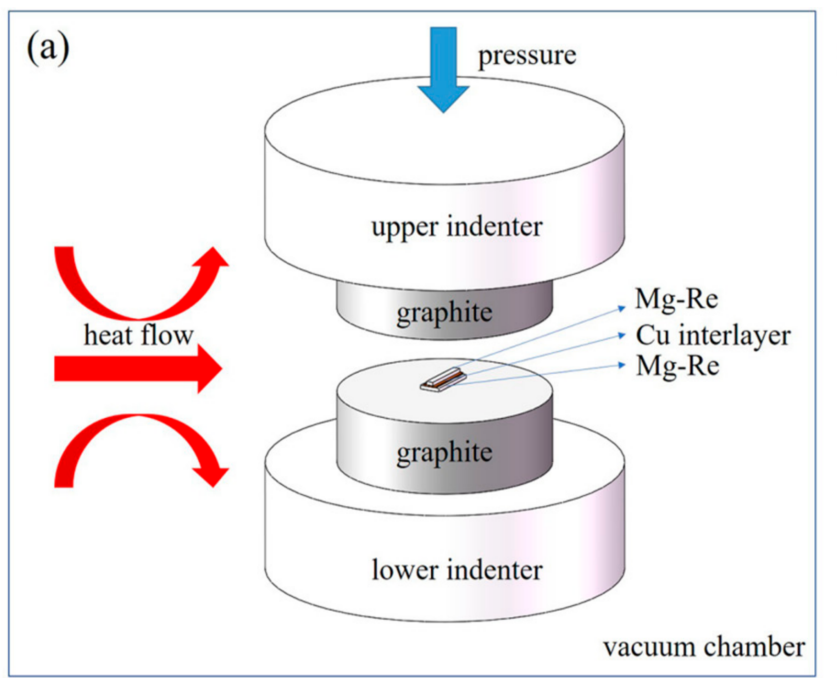

(b)
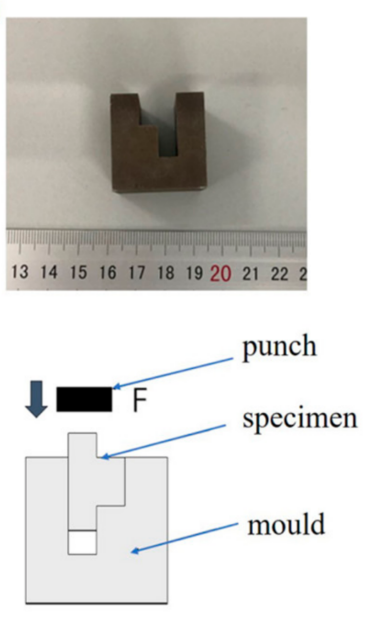

Figure 1. (a) Schematic diagram of the vacuum diffusion bonding, (b) Schematic diagram of shear test.

Table 1. Diffusion bonding parameters in the present study.

\begin{tabular}{ccccc}
\hline Sample & Temperature $\left({ }^{\circ} \mathbf{C}\right)$ & Pressure $(\mathbf{M P a})$ & Time $(\mathbf{m i n})$ & Interfacial Roughness (\#) \\
\hline S1 & 440 & 2 & 30 & 180 \\
S2 & 440 & 2 & 30 & 800 \\
S3 & 440 & 2 & 30 & 1500 \\
S4 & 460 & 2 & 30 & 180 \\
S5 & 460 & 2 & 30 & 800 \\
S6 & 460 & 2 & 30 & 1500 \\
S7 & 480 & 2 & 30 & 180 \\
S8 & 480 & 2 & 30 & 800 \\
S9 & 480 & 2 & 30 & 1500 \\
\hline
\end{tabular}

The SPF and RDB process of the double hollow structure was carried out on a $100 \mathrm{t}$ four-column hydraulic press (Hefei Haide CNC Hydraulic Equipment Co., LTD, Hefei, China). The superplastic forming and diffusion bonding temperature was $475{ }^{\circ} \mathrm{C}$ and $460{ }^{\circ} \mathrm{C}$, respectively. The target strain rate of the SPF process was $1 \times 10^{-3} \mathrm{~s}^{-1}$.

\section{Results and Discussion}

\subsection{Superplastic Characteristics of Mg-Re Alloy}

The effect of temperature and strain rate on the true stress-logarithmic strain curves for the Mg-Re alloy is shown in Figure 2. The temperature ranges from $250{ }^{\circ} \mathrm{C}$ to $450{ }^{\circ} \mathrm{C}$ while the strain rate ranges from $5 \times 10^{-4} \mathrm{~s}^{-1}$ to $1 \times 10^{-2} \mathrm{~s}^{-1}$. The alloy has been found to exhibit obvious superplastic deformation with an elongation of $1276.3 \%$ (a true strain of 2.47) at $400{ }^{\circ} \mathrm{C}$ under a strain rate of $1 \times 10^{-3} \mathrm{~s}^{-1}$. Thus, it can be concluded that the Mg-Re alloy exhibits superplastic-like large elongation. The flow stress decreases with increasing temperatures, and the material exhibits flow softening behavior after the flow stress peaks. The flow stress increases with increasing strain rates ranging from $1 \times 10^{-3} \mathrm{~s}^{-1}$ to $1 \times 10^{-2} \mathrm{~s}^{-1}$. It is worth noting that the elongation of the specimens at $0.0005 \mathrm{~s}^{-1}$ is low than that at $0.001 \mathrm{~s}^{-1}$, which might attribute to the oxidation at a slow stain rate. The material also experiences a positive strain rate sensitivity, which can be described by a power-law [17]:

$$
\sigma=K \dot{\varepsilon}^{m}
$$


where $m$ is the strain sensitivity coefficient indicated the effect of strain rate on the flow stress. $\mathrm{K}$ is the material constant related to the deformation temperature and the microstructure. Equation (1) was taken for the logarithms, and then it was expressed as:

$$
\ln \sigma=\ln K+m \ln \dot{\varepsilon}
$$

(a)

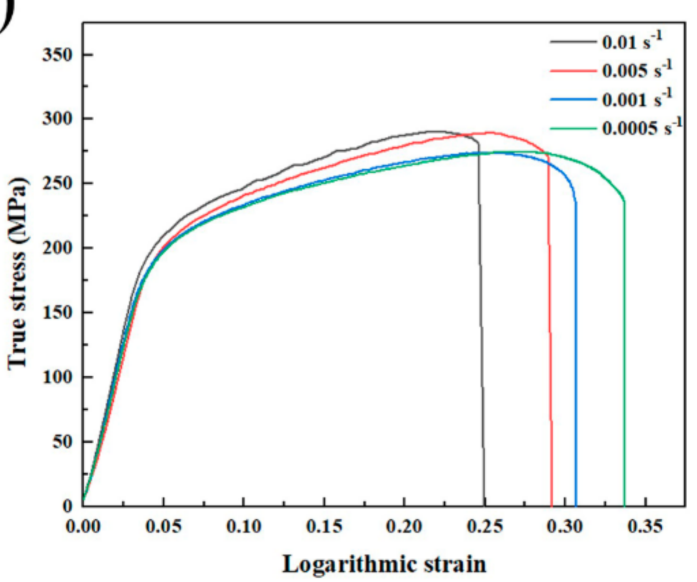

(c)

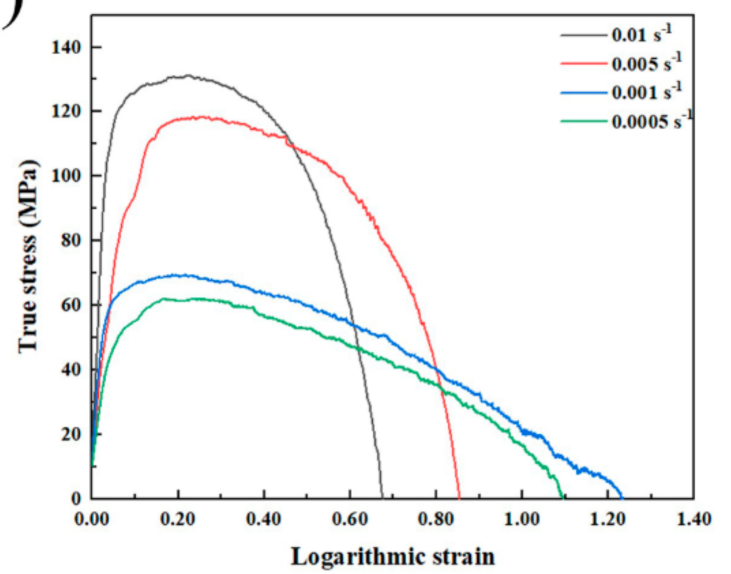

(b)

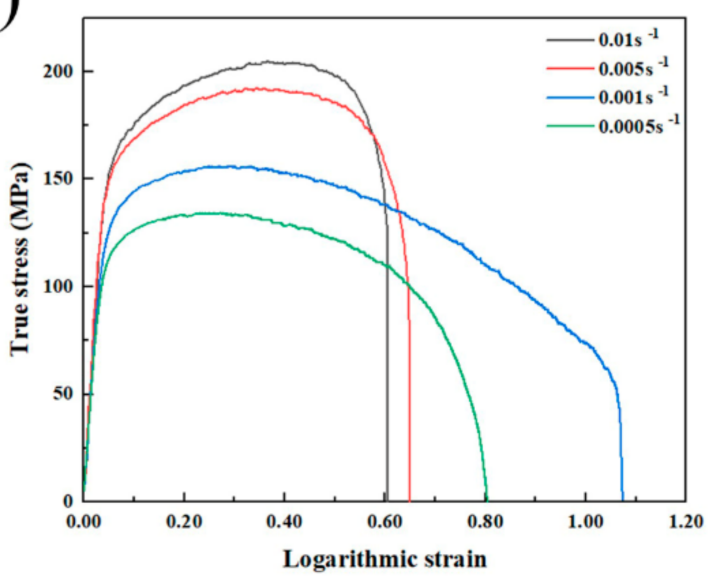

(d)

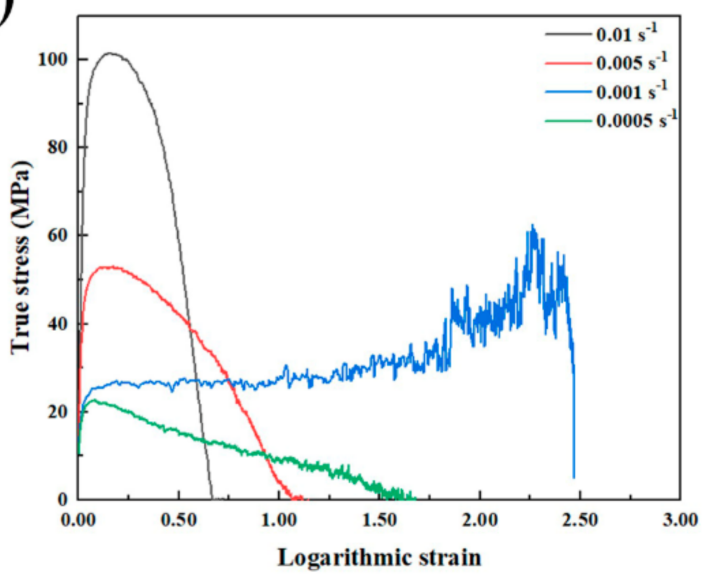

(e)

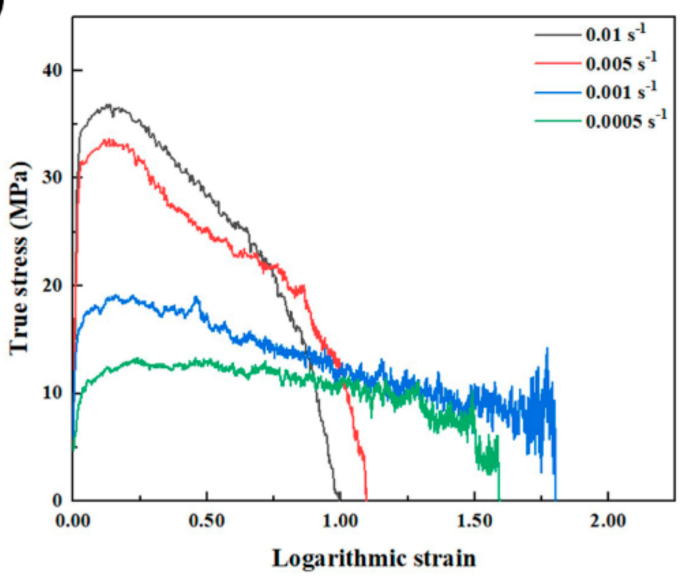

Figure 2. The true stress-logarithmic strain curves of Mg-Re alloys. (a) $250{ }^{\circ} \mathrm{C}$; (b) $300{ }^{\circ} \mathrm{C}$; (c) $350{ }^{\circ} \mathrm{C}$; (d) $400{ }^{\circ} \mathrm{C}$; (e) $450{ }^{\circ} \mathrm{C}$. 
For Equation (2), after being differential, the equation for $\mathrm{m}$ can be obtained as:

$$
m=\frac{\partial \ln \sigma}{\partial \ln \dot{\varepsilon}}
$$

The data obtained by the tensile test are nominal stress-strain curves. In order to accurately analyze the test results, it is necessary to convert the curves into true stresslogarithmic strain curves, and the conversion formulas are as follows:

$$
\begin{gathered}
\sigma=\frac{F}{A}=\frac{F}{A_{0}}\left(1+\frac{\Delta l}{l_{0}}\right) \\
\varepsilon=\ln \left(\frac{l}{l_{0}}\right)=\ln \left(1+\frac{\Delta l}{l_{0}}\right)
\end{gathered}
$$

where $\sigma$ is the true stress, $\varepsilon$ is the true strain, $\mathrm{F}$ is the loading stress, $A_{0}$ is the initial crosssectional area, $\Delta l$ is the deformation of tensile specimens, and $l_{0}$ is the standard distance of specimens.

Figure 3a shows the true stress-logarithmic strain responses under different strain rates at $400{ }^{\circ} \mathrm{C}$. The flow stress is cited as the logarithmic stress at the true strain of 0.25 , where the material is in a relatively stable deformation stage. The strain rate sensitivity exponent $\mathrm{m}$ can be determined from the logarithm of tensile stress versus logarithmic strain rates, as shown in Figure 3b. The value of $\mathrm{m}$ is calculated to be $0.51, \mathrm{~K}$ is estimated to be $1038.03 \mathrm{MPa} \cdot \mathrm{s}$ on account of the flow stress curves at $400{ }^{\circ} \mathrm{C}$ with different strain rates. Hidetoshi Somekawa [18] summarized that the flow stress of the extruded AZ31 alloy has little strain rate dependence, and the $\mathrm{m}$-values are $\sim 0.01$. Besides, the $\mathrm{m}$-values of $\mathrm{Mg}$-Bi alloys are calculated to be $0.22-0.30$. The obtained $\mathrm{m}$-values in the present alloys are 0.51 , grain-boundary sliding is known to be the rate-controlling mechanism [19]. Thus, the material in this paper could be applied to the SPF process.

(a)

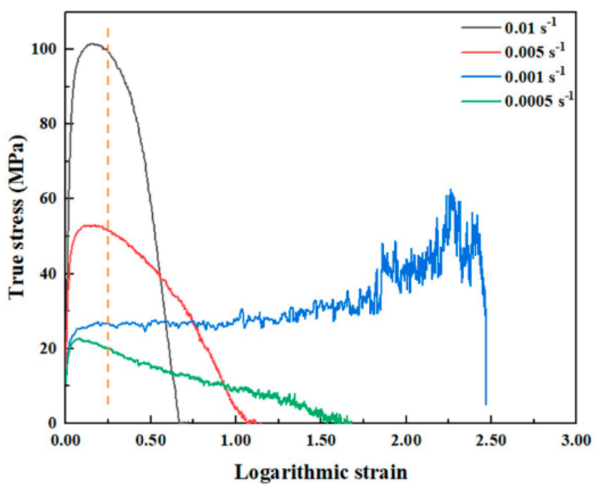

(b)

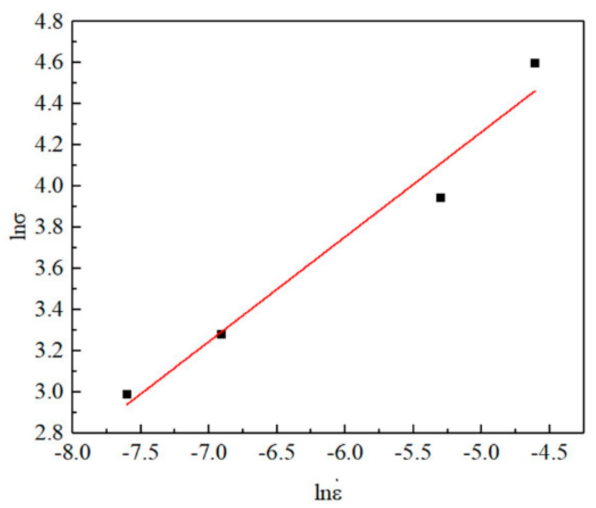

Figure 3. (a) The true stress-logarithmic strain curves of $\mathrm{Mg}$-Re alloy at $400{ }^{\circ} \mathrm{C}$ (taking the logarithmic strain at 0.25 for calculating the value of $\mathrm{m}$ ); (b) Plot of the logarithm of tensile stress versus logarithmic strain rate to determine the strain rate sensitivity $\mathrm{m}$.

\subsection{Interface Microstructure and Shear Strength}

\subsubsection{Bond Formation Mechanism Assisted with Pure $\mathrm{Cu}$ Interlayer}

According to the $\mathrm{Mg}-\mathrm{Cu}$ binary phase diagram shown in Figure 4, the melting point of $\mathrm{Cu}$ is $1084.87^{\circ} \mathrm{C}$, while $\mathrm{Mg}$ is $649^{\circ} \mathrm{C}$. The possible reaction products of $\mathrm{Mg}$ and $\mathrm{Cu}$ may be $\mathrm{Mg}_{2} \mathrm{Cu}$ and $\mathrm{MgCu}_{2}$ intermetallic compounds. Significantly, the solubility of $\mathrm{Mg}$ in Cu was about 4 at. \%, while $\mathrm{Cu}$ was almost insoluble in $\mathrm{Mg}$. The integrated morphology of diffusion bonding joints at $440^{\circ} \mathrm{C}, 1500$ \# for $30 \mathrm{~min}$ under $2 \mathrm{MPa}$ is shown in Figure 5 . The joint can be divided into three zones from left to right: $\mathrm{Mg}$-Re substrate zone, copper diffusion and reaction zone, and Mg-Re substrate zone. In order to determine the composition of the interface microstructure, the spectroscopic point scanning analysis was performed on the 
phases with a characteristic morphology, and the EDS analysis results are shown in Table 2. It can be concluded that point a near the weld and its similar microstructure are $\mathrm{Cu}(\mathrm{Mg})$ solid solution; point $\mathrm{b}$ inside the grain which is in the reaction zone may be $\alpha-\mathrm{Mg}$; the light grey phase (point c) between grain boundaries could be $\mathrm{MgCu}_{2}$, and the white spherical particles (point $\mathrm{d}$ ) are probably $\mathrm{Mg}_{2} \mathrm{Cu}$.

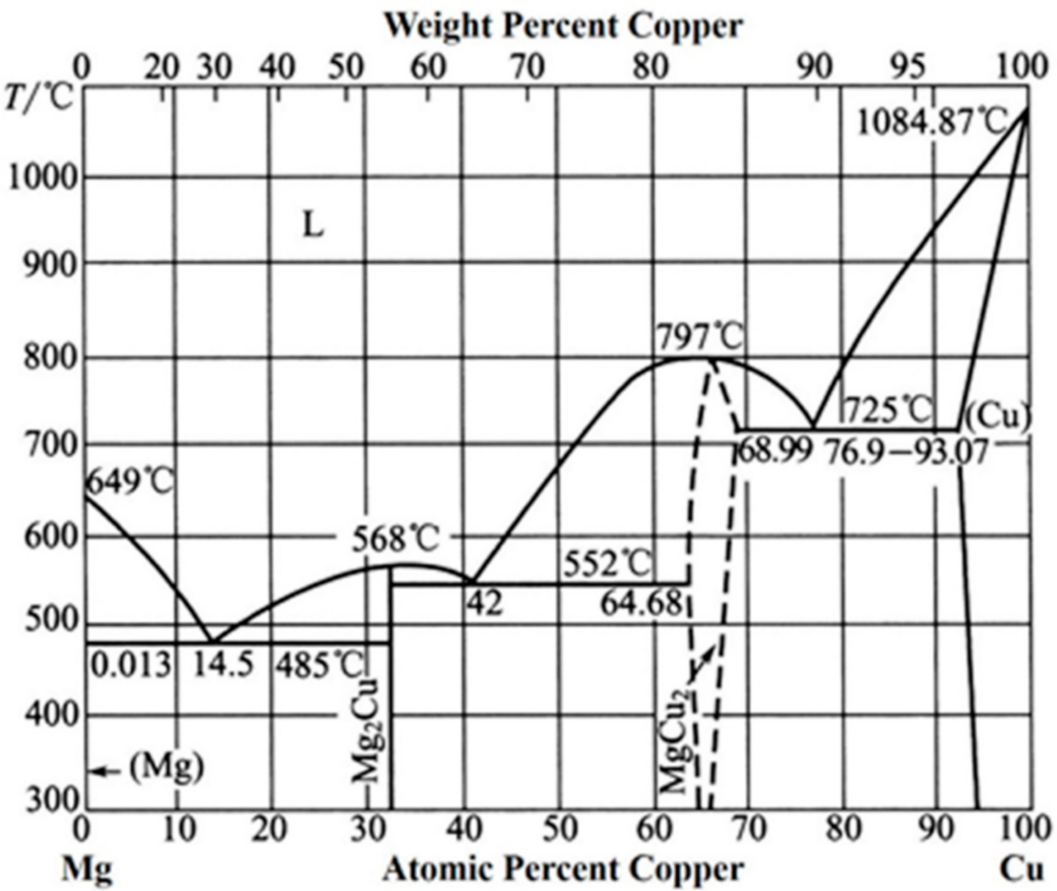

Figure 4. Mg-Cu binary phase diagram [20].
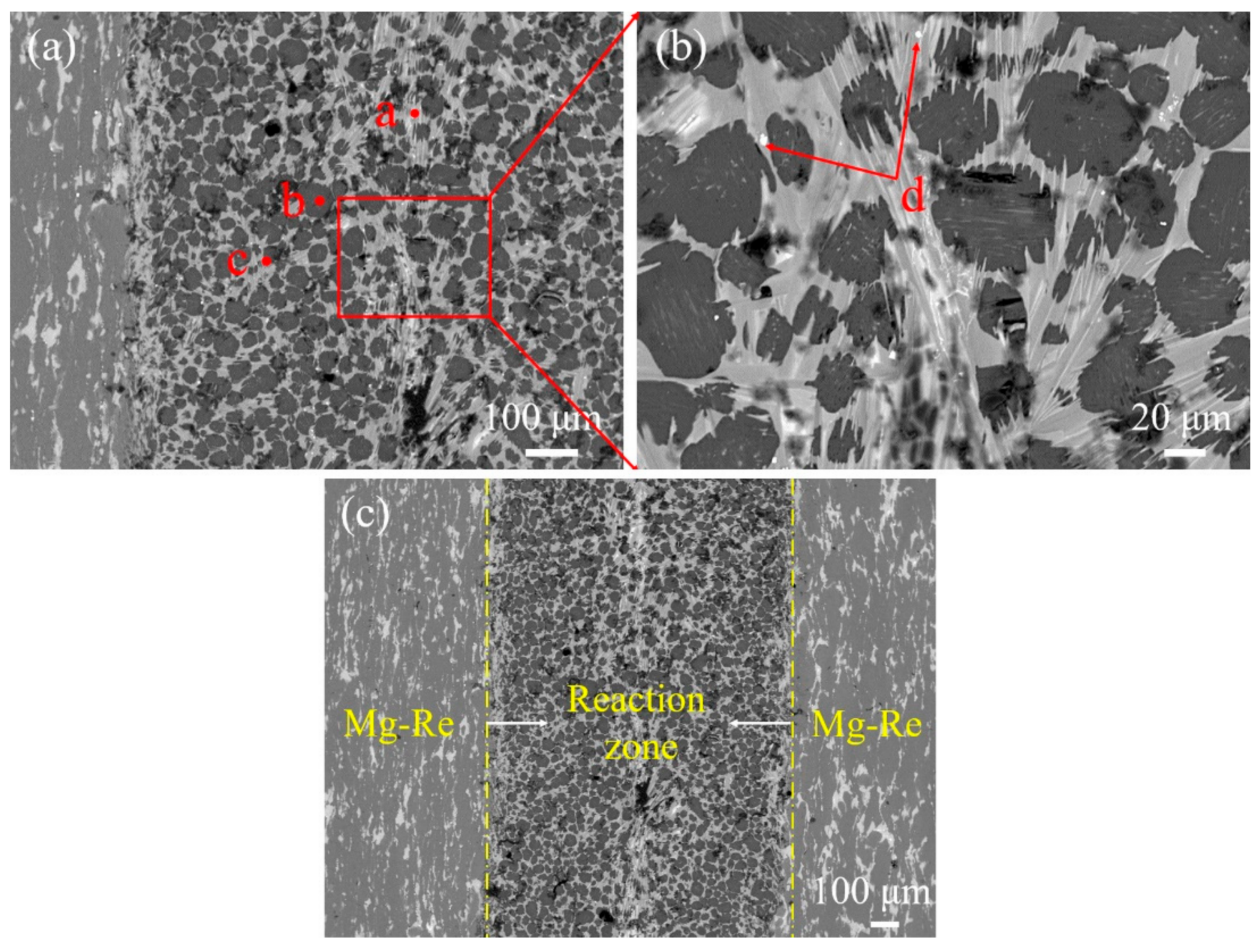

Figure 5. Microstructure of diffusion bonding joint at $440{ }^{\circ} \mathrm{C}, 1500 \#$ for 30 min under $2 \mathrm{MPa}$. (a) the microstructure of the weld, (b) partial enlargement of a figure (a), (c) different zones at the weld. 
Table 2. EDS analysis results of locations in Figure 2a,b.

\begin{tabular}{cccc}
\hline \multirow{2}{*}{ Locations } & \multicolumn{2}{c}{ Composition (at.\%) } & \multirow{2}{*}{ Possible Phase } \\
\cline { 2 - 3 } & $\mathbf{M g}$ & $\mathbf{C u}$ & $\mathrm{Cu}(\mathrm{Mg})$ \\
a & 3.21 & 96.79 & $\alpha-\mathrm{Mg}$ \\
b & 95.62 & 4.38 & $\mathrm{MgCu} 2$ \\
c & 32.18 & 67.82 & $\mathrm{Mg}_{2} \mathrm{Cu}$ \\
d & 68.47 & 31.53 & \\
\hline
\end{tabular}

It has been shown that heating binary metals in close contact will activate the atoms. Due to the concentration gradient, heterogeneous atoms diffuse to form a solid solution until one reaches its solid solubility. Subsequently, the organization loses its stability and forms a new crystal nucleus, which continuously grows to form a new phase, the intermetallic compound layer. According to the melting point of $\mathrm{Mg}$ and $\mathrm{Cu}$, diffusion transfer of $\mathrm{Mg}$ occurs more easily than $\mathrm{Cu}$ at the same temperature. At the initial stage of diffusion, saturated $\mathrm{Cu}(\mathrm{Mg})$ solid solution formed immediately on the copper side due to the limited solid solubility of $\mathrm{Mg}$ in $\mathrm{Cu}$. With the extension of holding time, the $\mathrm{MgCu}_{2}$ intermetallic compound layer generates owing to the instability of the supersaturated solid solution. As for the side of the $\mathrm{Mg}$ substrate zone, the activated $\mathrm{Cu}$ atoms prefer to diffuse along the grain boundaries where dislocations, vacancies, and other defects exist. When the atomic percentage of $\mathrm{Mg}$ and $\mathrm{Cu}$ reaches 2:1, the $\mathrm{Mg}_{2} \mathrm{Cu}$ phase precipitates out.

Figure 6 shows the SEM-EDS element distribution maps of all elements of the joint bonding at $480{ }^{\circ} \mathrm{C}, 1500 \#$ for 30 min under $2 \mathrm{MPa}$. It can be seen that the bright area is the enrichment phase of rare earth elements and magnesium-copper compounds, which distribute near grain boundaries, while the dark area is magnesium or magnesium-based solid solution, which distribute inside the grains. Cu element is evenly distributed. This proves once again that $\mathrm{Cu}$ diffused along grain boundaries. Taking the middle part of the circle in Figure 3 as an example, the distributions of $\mathrm{Cu}, \mathrm{Zn}$, and rare earth elements are much the same, mostly distributed near the grain boundaries. It is confirmed again that $\mathrm{Cu}$, $\mathrm{Zn}$, and rare earth elements prefer to diffuse along the grain boundaries. Figure 7 shows the TEM-EDS element distribution maps of all elements of the joint bonding at $480{ }^{\circ} \mathrm{C}$, $1500 \#$ for 30 min under $2 \mathrm{MPa}$. It can be seen that the width of the weld containing blocky particles and non-eutectic phases is approximately $0.5 \mu \mathrm{m}$. The particles in the vicinity of the weld are mainly composed of $\mathrm{Cu}, \mathrm{Zn}, \mathrm{Y}, \mathrm{Zr}$ elements, and the generates with multiple elements need to be further investigated.

\subsubsection{Effect of Bonding Temperature on the Microstructure of Mg-Re Alloy}

For diffusion bonding with the addition of an intermediate layer, the effect of temperature on the diffusion joint can be summarized as follows: (1) the movement ability of atoms at the interface, which means the diffusion ability of $\mathrm{Mg}$ and $\mathrm{Cu}$ elements; (2) phase transformation and recrystallization process of the joint organization.

The relationship between diffusion coefficient and temperature can be expressed by the Arrhenius-type equation (Equation (4)) [13]

$$
\mathrm{D}=\mathrm{D}_{0} \exp (-\mathrm{Q} / \mathrm{RT})
$$

where $\mathrm{D}$ is diffusion coefficient $\left(\mathrm{m}^{2} \cdot \mathrm{s}^{-1}\right)$; $\mathrm{D}_{0}$ is the proportionality constant $\left(\mathrm{m}^{2} \cdot \mathrm{s}^{-1}\right)$, independent of temperature for Equation (4) is valid; $Q$ is the activation energy $\left(\mathrm{J} \cdot \mathrm{mol}^{-1}\right)$; $\mathrm{R}$ is the molar gas constant $\left(8.314 \mathrm{~J} \cdot \mathrm{mol}^{-1} \cdot{ }^{\circ} \mathrm{C}^{-1}\right)$; $\mathrm{T}$ is the temperature $\left({ }^{\circ} \mathrm{C}\right)$. 


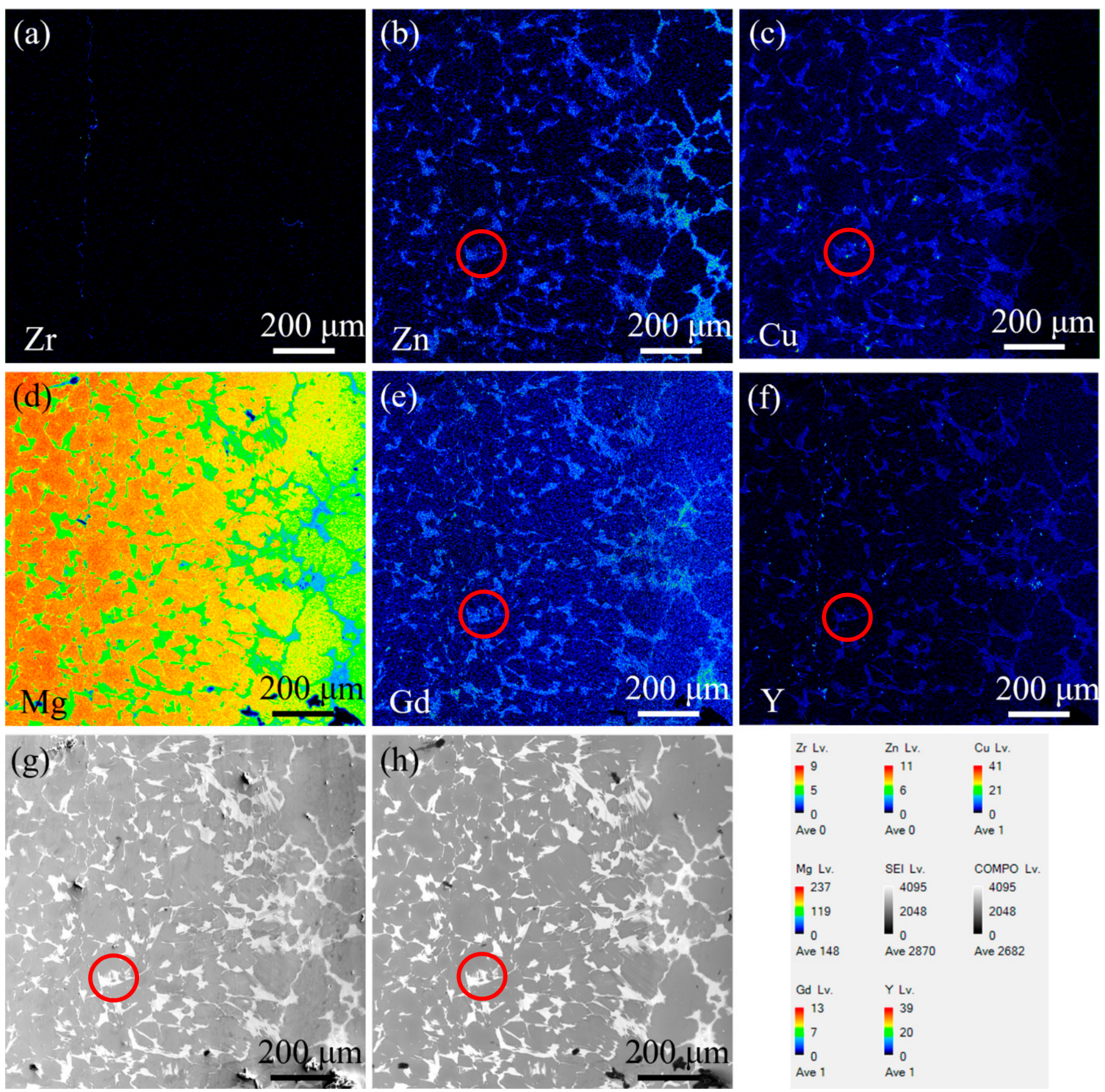

Figure 6. SEM-EDS element distribution maps of the joint bonding at $480{ }^{\circ} \mathrm{C}, 1500 \#$ for 30 min under $2 \mathrm{MPa}$ : (a) $\mathrm{Zr}$; (b) Zn; (c) $\mathrm{Cu}$; (d) Mg; (e) $\mathrm{Gd}$; (f) $\mathrm{Y}$; (g) and (h) SEM microstructure image of the joint.

Table 3 shows the proportionality constant and activation energy of $\mathrm{Mg}$ and $\mathrm{Cu}$. The diffusion coefficient of the element at any temperature can be obtained according to the Arrhenius-type equation. It is calculated that the diffusion coefficient of $\mathrm{Cu}$ atoms in $\mathrm{Mg}$ crystals is much larger than that of $\mathrm{Mg}$ atoms in $\mathrm{Cu}$ crystals at the same temperature. Taking $440{ }^{\circ} \mathrm{C}$ as an example, the diffusion coefficient of $\mathrm{Cu}$ atoms in $\mathrm{Mg}$ crystals is $1.07 \times 10^{-12} \mathrm{~m}^{2} \cdot \mathrm{s}^{-1}$, while that of $\mathrm{Mg}$ atoms in $\mathrm{Cu}$ crystals is $0.83 \times 10^{-16} \mathrm{~m}^{2} \cdot \mathrm{s}^{-1}$. The difference between them is 4 orders of magnitude, which is why the area of the Cu-based solid solution zone in the diffusion interface is much smaller than that of $\mathrm{MgCu}_{2}$. 


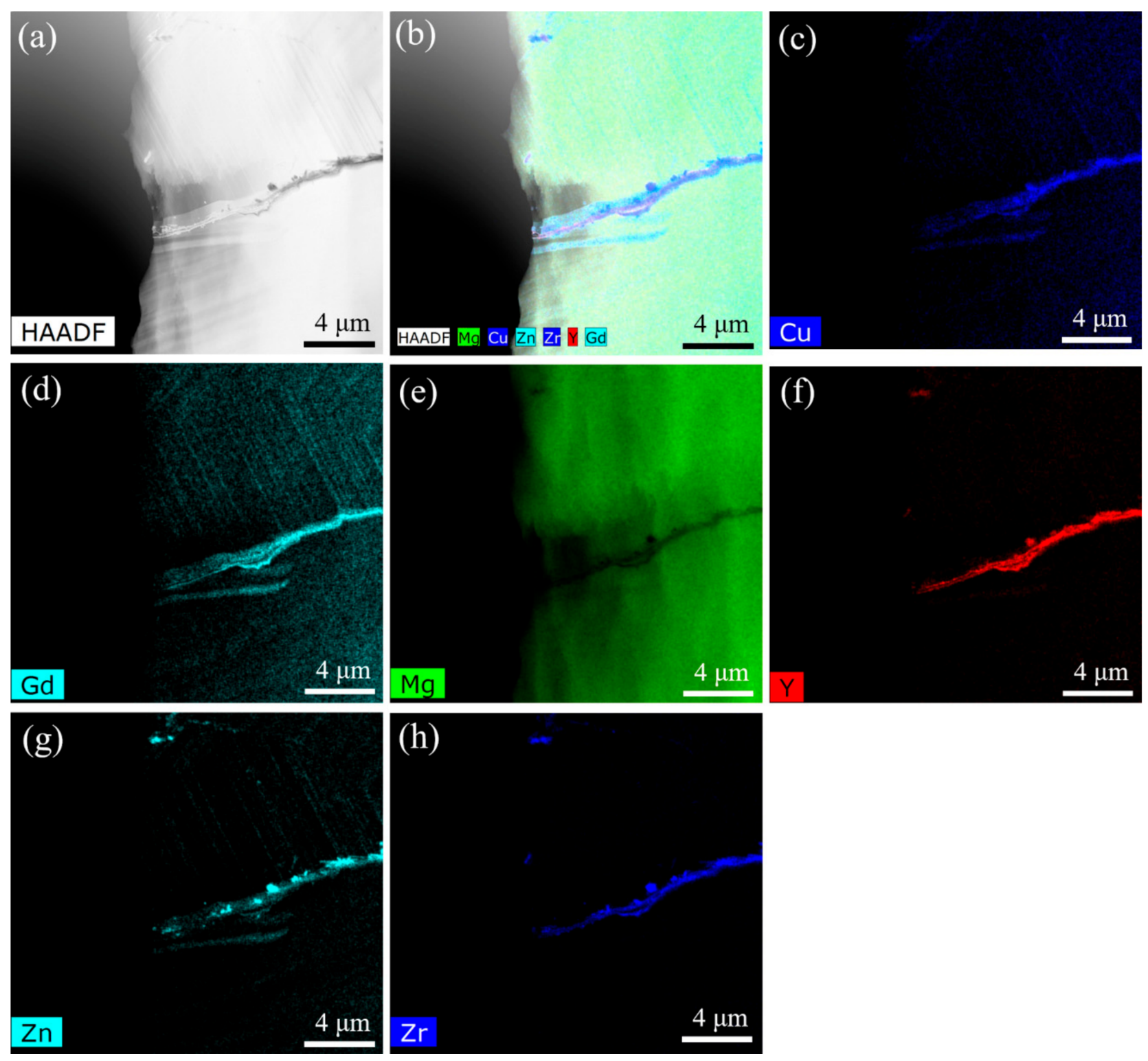

Figure 7. TEM-EDS analyses of the joint bonding at $480^{\circ} \mathrm{C}, 1500 \#$ for $30 \mathrm{~min}$ under $2 \mathrm{MPa}$ : (a) HAADFSTEM image of the joint; (b) STEM-EDS mapping image of all elements; STEM-EDS elemental mapping images for (c) $\mathrm{Cu}$; (d) $\mathrm{Gd}$; (e) $\mathrm{Mg}$; (f) $\mathrm{Y}$; (g) $\mathrm{Zn}$ (h) $\mathrm{Zr}$.

Table 3. Proportionality constant and activation energy of $\mathrm{Mg}$ and $\mathrm{Cu}$.

\begin{tabular}{ccccc}
\hline & $\mathbf{M g}$ & $\mathbf{C u}$ & $\mathbf{M g}$ in Cu & $\mathbf{C u}$ in $\mathbf{M g}$ \\
\hline $\mathrm{D}_{0}\left(\mathrm{~m}^{2} \cdot \mathrm{s}^{-1}\right)$ & $1.5 \times 10^{-4}$ & $0.2 \times 10^{-4}$ & $5.2 \times 10^{-6}$ & $1.1 \times 10^{-3}$ \\
$\mathrm{Q}\left(\mathrm{J} \cdot \mathrm{mol}^{-1}\right)$ & $1.4 \times 10^{5}$ & $2.0 \times 10^{5}$ & $1.5 \times 10^{5}$ & $1.2 \times 10^{5}$ \\
\hline
\end{tabular}

Figure 8 shows the microstructure of the diffusion interface at different temperatures with the same roughness. According to Equation (4), we can know that the mutual diffusion coefficient between $\mathrm{Mg}$ and $\mathrm{Cu}$ atoms has an exponential growth relationship with temperature. Therefore, the area of the $\mathrm{MgCu}_{2}$ phase and the width of the reaction zone increase as the temperature rises. When the temperature elevated from $440{ }^{\circ} \mathrm{C}$ to $460{ }^{\circ} \mathrm{C}$, the grain size of $\alpha-\mathrm{Mg}$ grows slightly, with an average size of about $30 \mu \mathrm{m}$. In contrast, it grows to about $70 \mu \mathrm{m}$ at $480{ }^{\circ} \mathrm{C}$, which may greatly impact the strength of the joints. 

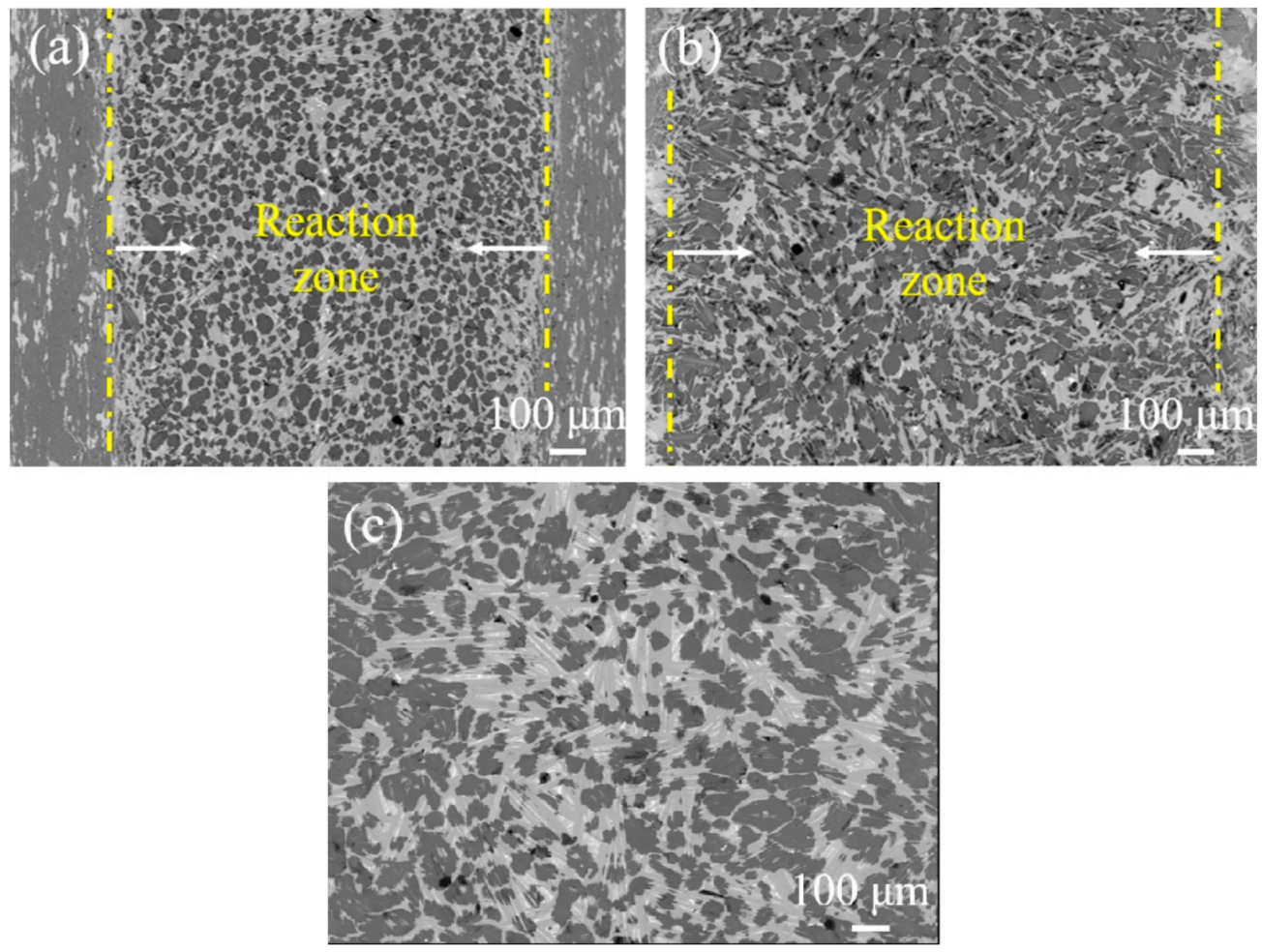

Figure 8. Microstructure of the diffusion bonding joint with the interfacial roughness of $800 \#$. (a) $440{ }^{\circ} \mathrm{C}$ (b) $460{ }^{\circ} \mathrm{C}$ (c) $480{ }^{\circ} \mathrm{C}$.

Figure 9 shows the microstructure of the joint bonding at $440{ }^{\circ} \mathrm{C}, 180 \#$ for $30 \mathrm{~min}$ under $2 \mathrm{MPa}$. The EDS results of the highlighted point in Figure 8 show that $\mathrm{Cu}^{\prime} \mathrm{s}$ atomic percent is as high as 99.76. $\mathrm{Tt}$ is reasonable to assume that the $\mathrm{Cu}$ element is not completely diffused at this temperature. In conclusion, grain size growth is not obvious, and the diffusion of $\mathrm{Cu}$ is thorough at $460^{\circ} \mathrm{C}$, which means that $460^{\circ} \mathrm{C}$ may be the ideal diffusion bonding temperature of $\mathrm{Mg}$-Re alloy.

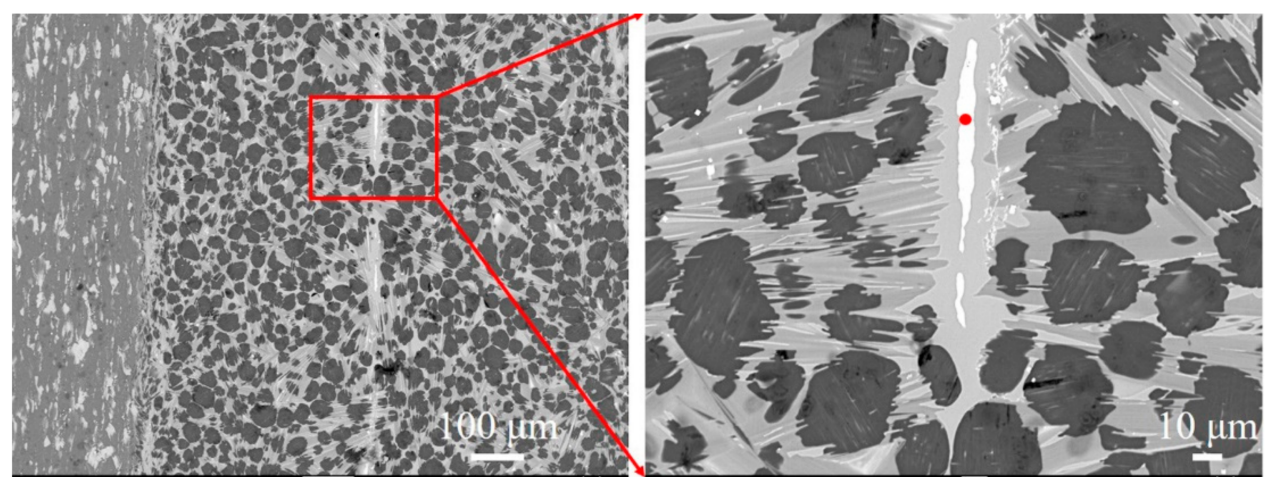

Figure 9. The microstructure of the joint bonding at $440{ }^{\circ} \mathrm{C}, 180 \#$ for $30 \mathrm{~min}$ under $2 \mathrm{MPa}$.

\subsubsection{Effect of Interface Roughness on the Microstructure of Mg-Re Alloy}

As for diffusion bonding without an intermediate layer, the roughness of the diffusion interface will significantly affect the micro-contact of the bonding interface. For relatively active metals, the diffusion bonding mechanism is as follows: the elongation of alloy and compact oxide film covered on the substrate is quite different; the oxide film breaks first, leading to local contact at the place of the rupture under the same deformation conditions. With the heat preservation and pressure retention, the oxide film continuously ruptures and begins to form eutectic planes, eventually forming a stable diffusion joint. However, for the 
diffusion bonding with the intermediate layer, the connection mechanism is mainly that the atoms at the interface are activated in a certain temperature and pressure conditions. The atoms of binary metals will mutually diffuse to form a solid solution owing to the concentration gradient between the heterogeneous elements. When the solid solubility reaches a supersaturated state of one of the elements, the organization loses its stability and forms a new crystal nucleus, which continuously grows to form a new phase, that is, the intermetallic compound layer, and finally form a stable diffusion joint.

Figure 10 shows the microstructure of the diffusion bonding joint at the same temperature with different roughness of interface. It can be seen that the widths of the reaction zone hardly change with different roughness. The grain sizes and the area of the intermetallic compound layer at the grain boundary are almost the same. This demonstrates that there is little relationship between diffusion coefficient and roughness of interface for reaction-diffusion bonding.
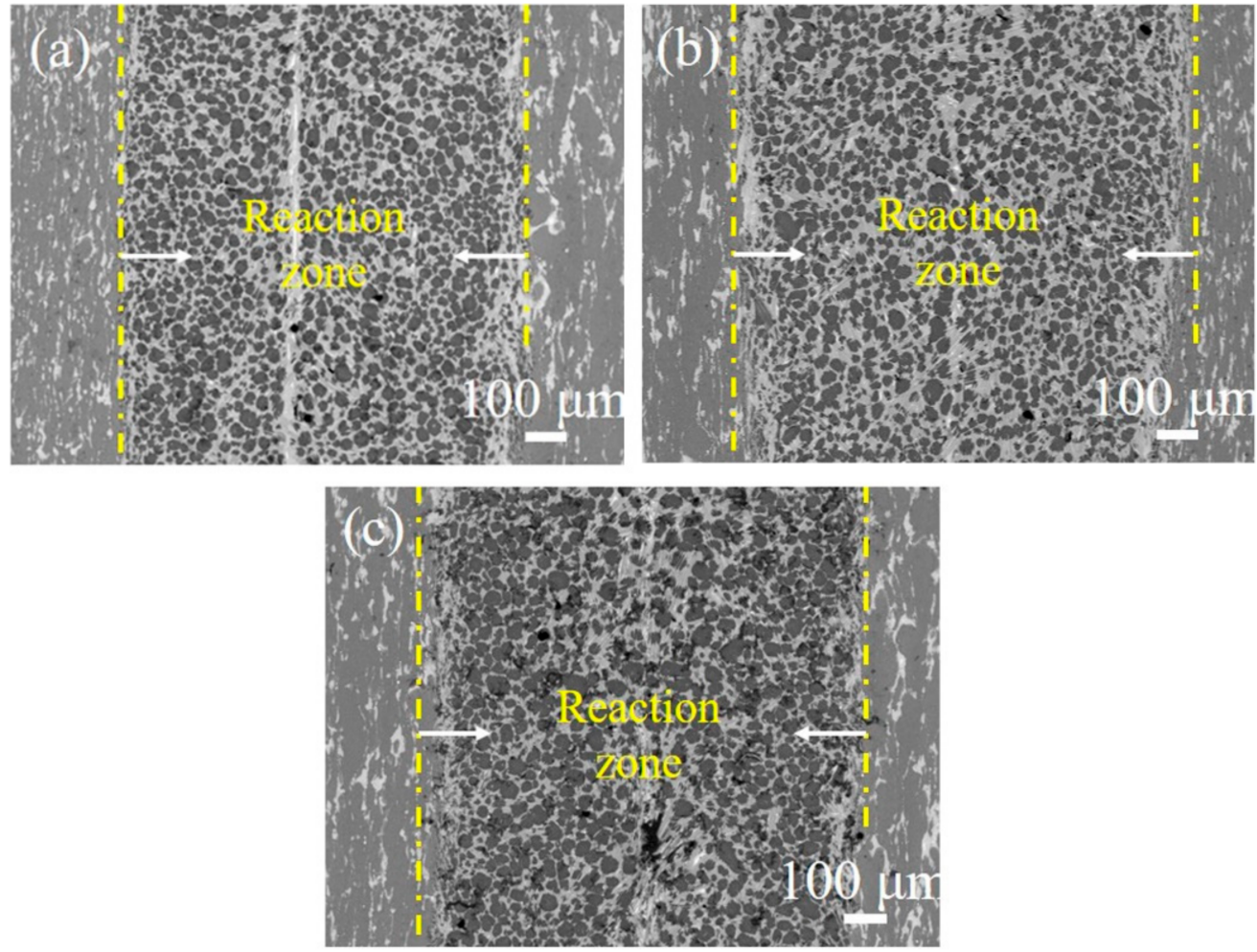

Figure 10. Microstructure of the diffusion bonding joint at $440{ }^{\circ} \mathrm{C}$ with different roughness of interface. (a) 180\# (b) $800 \#$ (c) 1500\#.

\subsubsection{Shear Strength of the Diffusion-Bonded Joints}

Figure 11 shows the shear strength of joints under different diffusion bonding conditions. It can be concluded that the shear strength is significantly influenced by the temperature, while there is little relationship between the shear strength and the roughness of the interface. The shear strength at $480^{\circ} \mathrm{C}(108 \mathrm{MPa})$ is generally low, which may be caused by the growth and softening of the grains. In contrast, the shear strength at $440{ }^{\circ} \mathrm{C}$ $(130 \mathrm{MPa})$ is relatively high though the diffusion of $\mathrm{Cu}$ is not thorough. Furthermore, the shear strength is up to $150 \mathrm{MPa}$ at $460{ }^{\circ} \mathrm{C}$. The grains of the interface at $460{ }^{\circ} \mathrm{C}$ grow inapparently, and the diffusion of the $\mathrm{Cu}$ element is relatively uniform. In order to verify the specific shear performance of the specimens after diffusion, the base material was cut into the same size as the shear samples, and the shear test was carried out. The shear strength of the base material was measured to reach $154 \mathrm{MPa}$. Take the highest strength specimen from nine groups for comparison; the shear strength of the specimen obtained after diffusion could reach $98.7 \%$ of the matrix. Figure 12 shows the image of the joint 
bonding at $440{ }^{\circ} \mathrm{C}$ and the base metal after the shear test. It is worth noting that the fracture of the specimen occurred at the base material rather than at the interface.

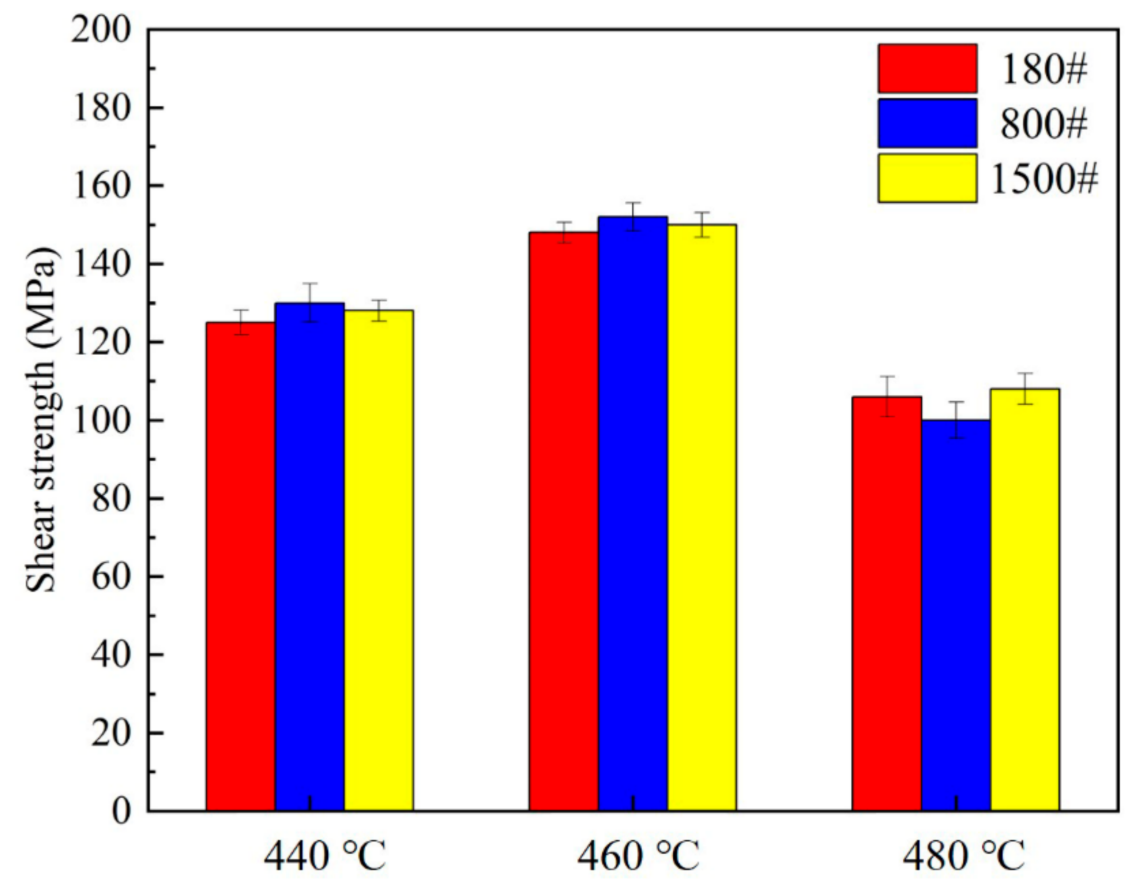

Figure 11. Shear strength of joints under different diffusion bonding conditions.

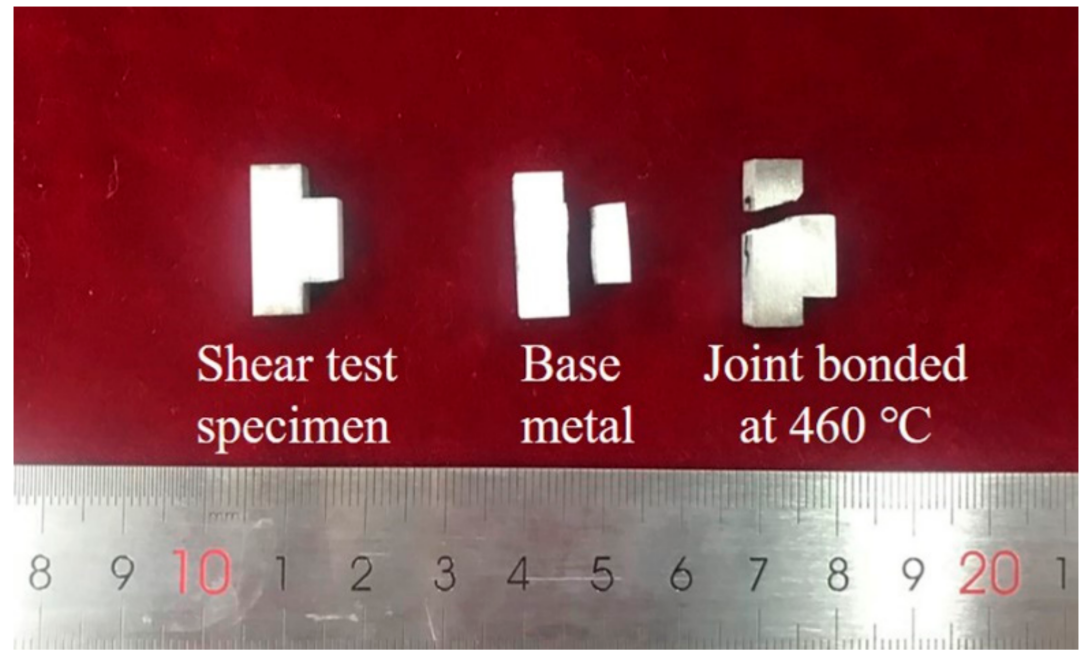

Figure 12. Image of the joint bonding at $440{ }^{\circ} \mathrm{C}$ and the base metal after shear test.

\subsection{Superplastic Forming and Reaction Diffusion Bonding of the Double Hollow} Structural Component

Figure 13 illustrates the sheet thickness distribution of a double hollow structural component during superplastic forming by finite element analysis (FEA). It has been demonstrated in Section 3.1 that Mg-Re alloy exhibits maximum ductility at the strain rate of $1 \times 10^{-3} \mathrm{~s}^{-1}$. Hence, the strain rate for FEA was set to be $1 \times 10^{-3} \mathrm{~s}^{-1}$. Due to the symmetry of the component, the simplified 1/2 model was applied for the FEA. There are 2500 elements in the component which are set as deformable, while the die is set as a rigid body. The Backofen equation describes the constitute equation of FEA, and the strain rate sensitivity coefficient $\mathrm{m}$ was chosen to be 0.51 with the material coefficient $\mathrm{K}=1038.03$, 
which are the same as stated in Section 3.1. Figure 14 shows the boundary conditions of the finite element model. Since argon gas pressure is the driving source for forming, the face load was applied to the whole sheet surface along the sheet's normal direction. During the forming process of the sheet, the diffusion bonding area did not participate in the deformation, so the node displacement was set to 0 , which meant displacement $\mathrm{X}=$ displacement $\mathrm{Y}=$ displacement $\mathrm{Z}=0$.
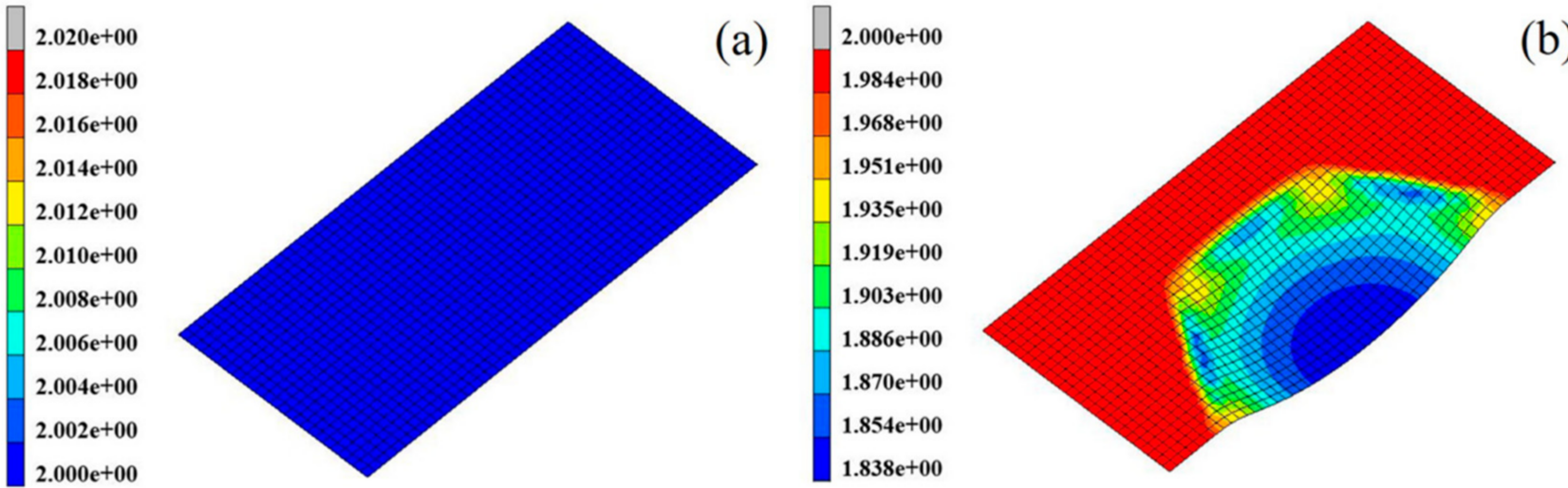

(b)
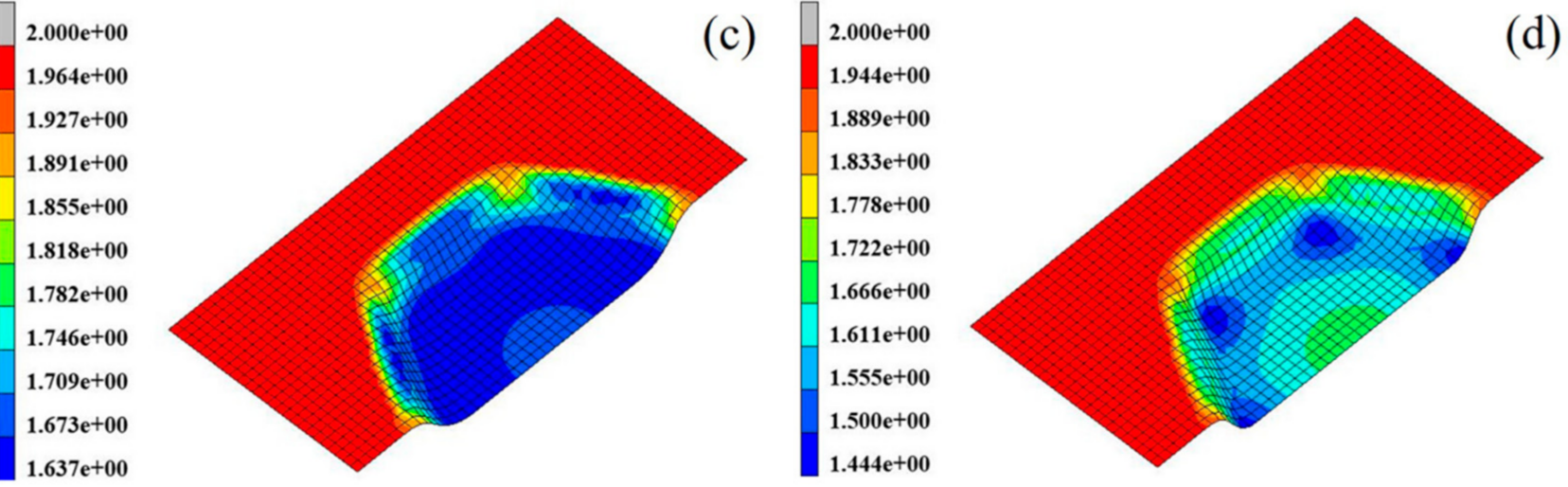

(d)
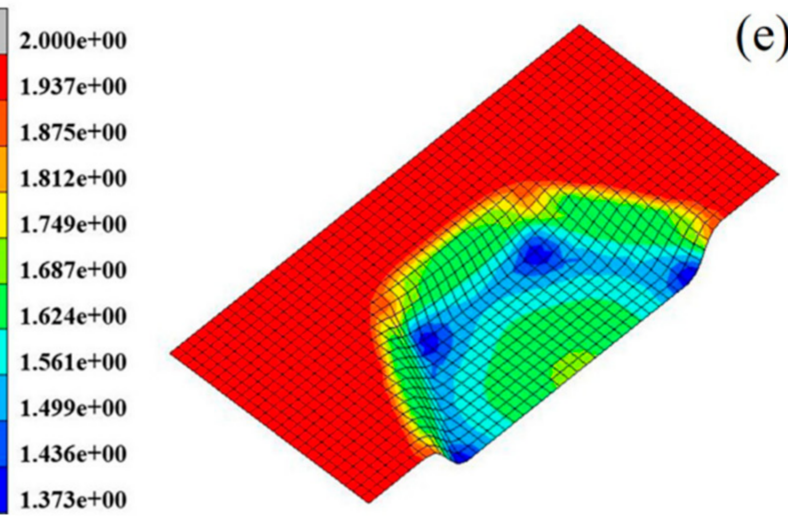

(e)
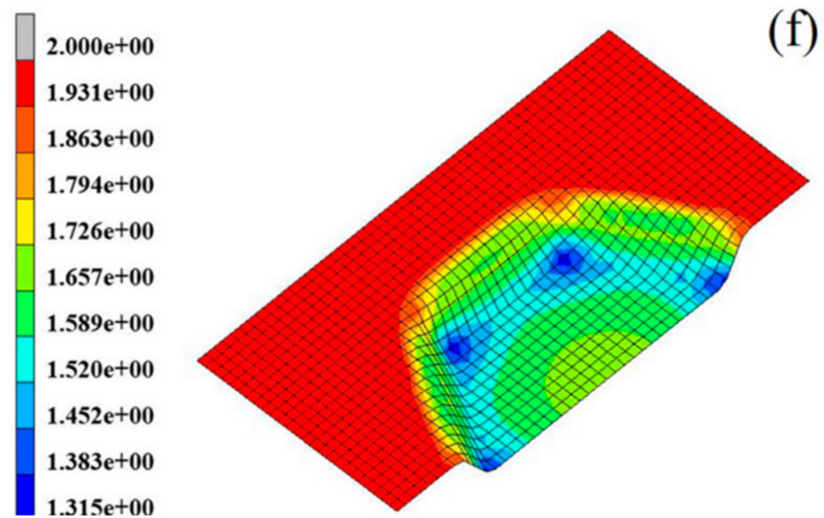

Figure 13. Thickness distribution of Mg-Re alloy at different stages of superplastic forming (a) 0s; (b) 50s; (c) 120s; (d) 250s; (e) 400s; (f) 547s.

In the beginning, the center section of the blank is brought into contact with the cavity and gets thinning. Then the forming process is hindered by the sheet/die interface friction. With the gradual increase of argon gas pressure, the blank continues to fit the mold. The round corner, which requires a larger forming force, was the thinnest part of the component during superplastic forming. 

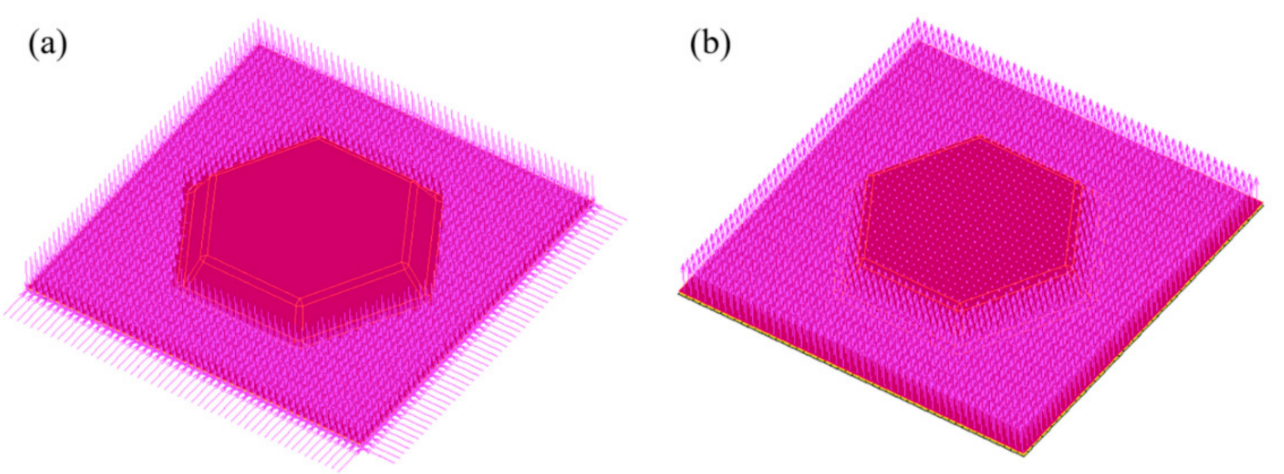

Figure 14. Boundary conditions of the finite element model (a) displacement boundary condition (b) face load boundary condition.

The thickness distribution from the flange to the bottom region of the final component predicted by FEA is shown in Figure 15. It can be seen that the thickness decreases gradually from $2 \mathrm{~mm}$ of the flange to $1.6 \mathrm{~mm}$ at the bottom of the component. In addition, the maximum thinning rate was $34 \%$ at the round corner.

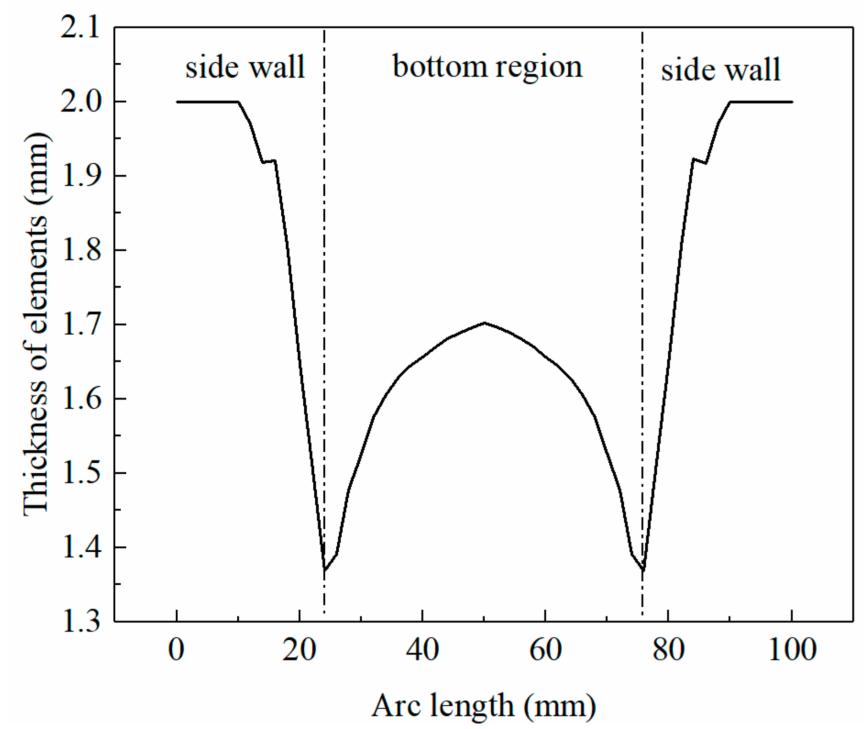

Figure 15. The thickness distribution of the component predicted by FEA.

Figure 16 illustrates different nodes' thickness variation with time and the process pressure predicted by FEA. It should be noted that the position of node 262 is at the round corner, while node 225 is at the bottom center of the component. The thickness of node 252 decreases rapidly from $2 \mathrm{~mm}$ to $1.7 \mathrm{~mm}$ and keeps stable. On the other hand, the rate of thickness thinning at node 262 slows down around $1500 \mathrm{~s}$, implying that more pressure is required for deformation at this time, which can be reflected in the process pressure-time curve, where the slope of the curve increases. Besides, the pressure-time curve predicted by FEA in Figure 15 can be used to guide the subsequent SPF process.

The SPF/RDB process is carried out to fabricate the hollow structural component on the superplastic forming machine (Hefei Haide CNC Hydraulic Equipment Co., LTD, Hefei, China). It has been demonstrated in Section 3.2 that the optimal temperature of the RDB is $460{ }^{\circ} \mathrm{C}$. Thus, the sheets are diffusion bonded at $460^{\circ} \mathrm{C}$ with argon gas pressure of $2 \mathrm{MPa}$ for about $30 \mathrm{~min}$. Subsequently, the SPF of the sheets is carried out at $400^{\circ} \mathrm{C}$ with the target strain rate of $0.001 \mathrm{~s}^{-1}$. The thickness distribution of the finished double hollow structural component is illustrated in Figure 17. Similar to results predicted by FEA in Figure 15, the thickness reduces dramatically at the round corner with a thinning rate of about $35 \%$. 
(a)

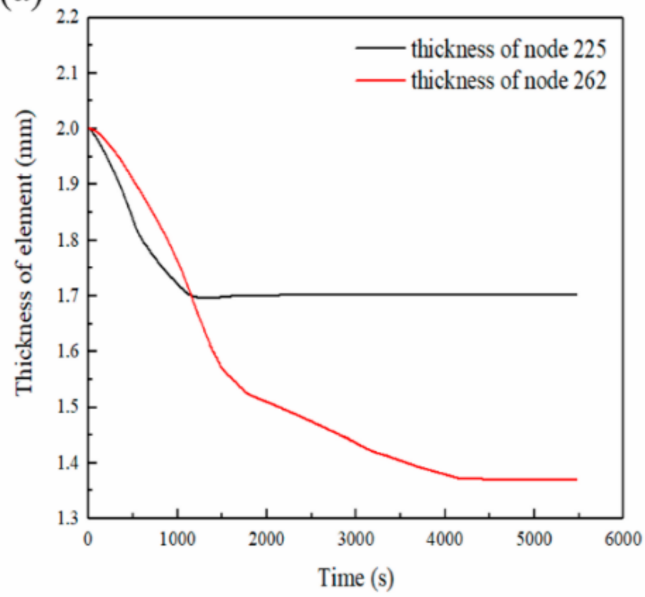

(b)

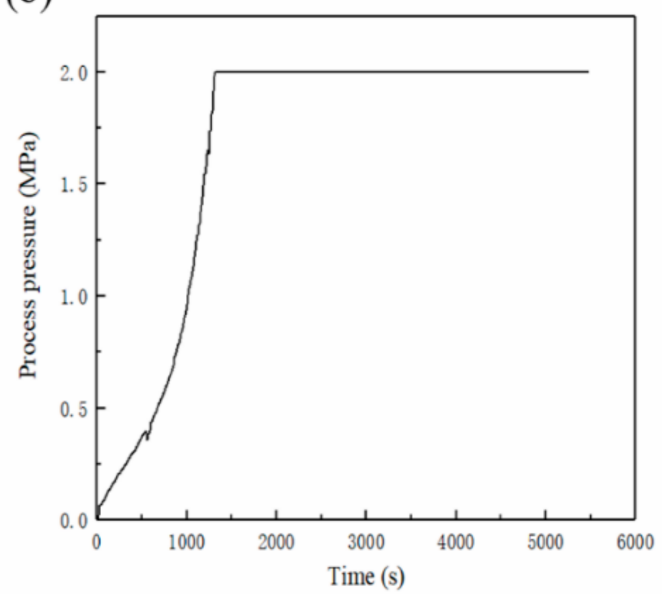

Figure 16. (a) The thickness-time curves of different nodes, (b) the process pressure-time curve predicted by FEA.
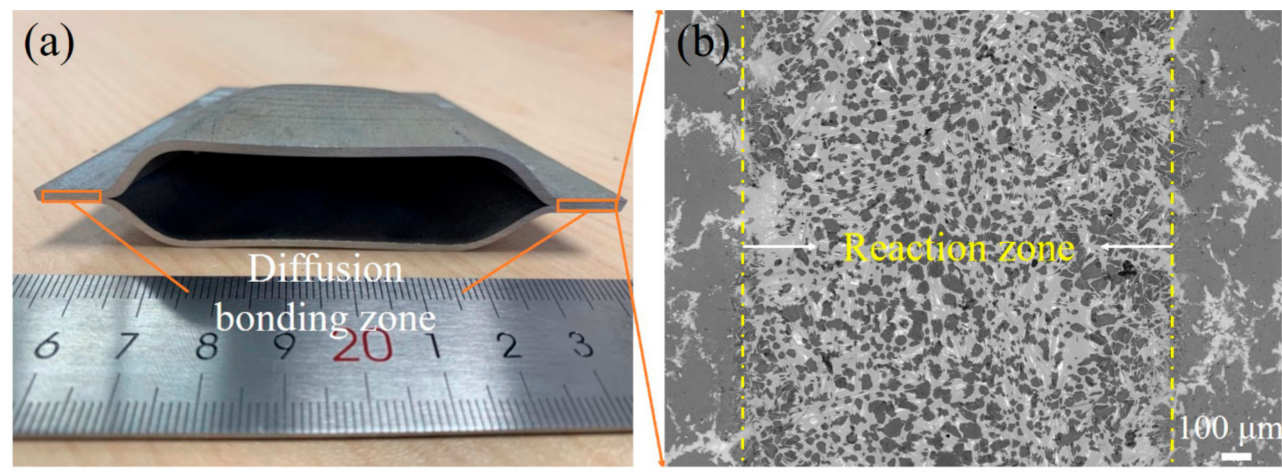

(c)

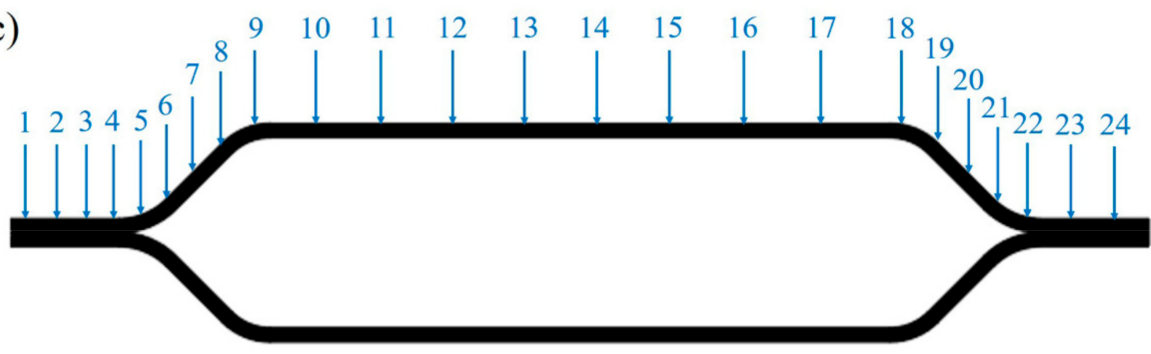

(d)

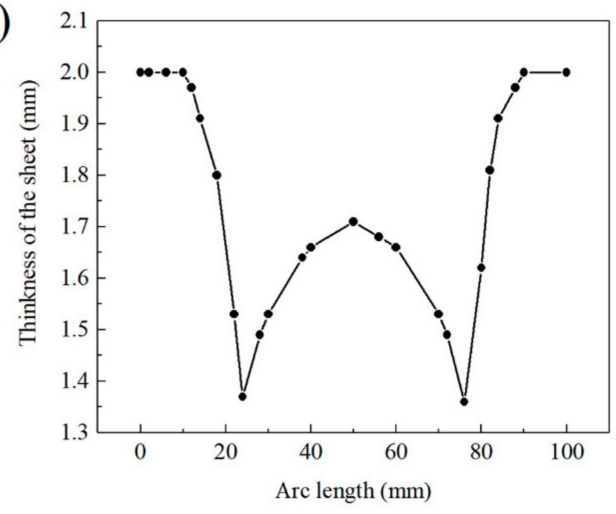

Figure 17. (a) The cross-section of the finished double hollow structural component; (b) microstructure of the diffusion bonding zone; (c) the position of thickness measurement; (d) The thickness distribution of the component. 


\section{Conclusions}

The superplastic characteristic and mechanical properties of Mg-8.3Gd-2.9Y-0.8Zn$0.2 \mathrm{Zr}$ alloy sheets at $250-450{ }^{\circ} \mathrm{C}$ were studied. Besides, the effect of bonding temperature and interface roughness on microstructure and mechanical properties of the reaction diffusion-bonded joints with a $\mathrm{Cu}$ interlayer was investigated in this paper. The following conclusions can be drawn:

The maximum elongation of $\mathrm{Mg}$-Re alloys is $1276.3 \%$ at $400{ }^{\circ} \mathrm{C}$ under a strain rate of $1 \times 10^{-3} \mathrm{~s}^{-1}$. The value of $\mathrm{m}$ and $\mathrm{K}$ at $400{ }^{\circ} \mathrm{C}$ is 0.51 and 1038.03 , respectively.

The area of $\mathrm{MgCu}_{2}$ phase and the width of the reaction zone increase as the temperature raises. Besides, the $\mathrm{Cu}$ element diffuses incompletely at $440{ }^{\circ} \mathrm{C}$. However, there is little relationship between diffusion coefficient and roughness of interface for reaction-diffusion bonding.

The shear strength is significantly influenced by the temperature, while there is little relationship between the shear strength and interface roughness. The highest shear strength of the joints is diffused at $460{ }^{\circ} \mathrm{C}$, reaching $152 \mathrm{MPa}$, which is $98.7 \%$ of the base metal.

Experimentally, a double hollow structural component was manufactured by SPF/RDB process. The thickness reduces dramatically at the round corner with a thinning rate of about $35 \%$.

Author Contributions: P.P.: literature search, data analysis, data interpretation, figures, writing, finite element analysis; S.J.: literature search, study design, data collection; Z.Q.: literature search, fund support, finite element analysis; Z.L.: study design, finite element analysis, literature search. All authors have read and agreed to the published version of the manuscript.

Funding: The National Natural Science Foundation of China (51775135) and the NSAF Joint Fund (U1830119).

Data Availability Statement: Not applicable.

Acknowledgments: The authors acknowledge the funding support from the National Natural Science Foundation of China (51775135) and the NSAF Joint Fund (U1830119).

Conflicts of Interest: The authors declare that they have no known competing financial interests or personal relationships that could have appeared to influence the work reported in this paper.

\section{References}

1. Horita, Z.; Matsubara, K.; Makii, K.; Langdon, T.G. A two-step processing route for achieving a superplastic forming capability in dilute magnesium alloys. Scr. Mater. 2002, 47, 255-260. [CrossRef]

2. Song, J.; She, J.; Chen, D.; Pan, F. Latest research advances on magnesium and magnesium alloys worldwide. J. Magnes. Alloy. 2020, 8, 1-41. [CrossRef]

3. Yang, Y.; Xiong, X.; Chen, J.; Peng, X.; Chen, D.; Pan, F. Research advances in magnesium and magnesium alloys worldwide in 2020. J. Magnes. Alloy. 2021, 9, 705-747. [CrossRef]

4. Taylor, S.; West, G.; Mogire, E.; Tang, F.; Kotadia, H. Superplastic forming characteristics of AZ41 magnesium alloy. Trans. Nonferrous Met. Soc. China 2021, 31, 648-654. [CrossRef]

5. Zhou, H.; Zhang, C.; Han, B.; Qiu, J.; Qin, S.; Gao, K.; Liu, J.; Sun, S.; Zhang, H. Microstructures and Mechanical Properties of Nanocrystalline AZ31 Magnesium Alloy Powders with Submicron $\mathrm{TiB}_{2}$ Additions Prepared by Mechanical Milling. Crystals 2020, 10, 550. [CrossRef]

6. Xu, C.; Nakata, T.; Fan, G.H.; Li, X.W.; Tang, G.Z.; Kamado, S. Enhancing strength and creep resistance of Mg-Gd-Y-Zn-Zr alloy by substituting Mn for Zr. J. Magnes. Alloy. 2019, 7, 388-399. [CrossRef]

7. Guomin, L.; Yongfu, W. Cover Structure Design of Titanium Alloy Based on the SPF/DB Process. DEStech Trans. Mater. Sci. Eng. 2017. [CrossRef]

8. Wang, N.; Chen, M.; Xie, L. Hot flow behavior characterization for predicting the titanium alloy TC4 hollow blade surface Sinkage defects in the SPF/DB process. Int. J. Mater. Form. 2018, 12, 827-844. [CrossRef]

9. Chandrappa, K.; Sumukha, C.S.; Sankarsh, B.B.; Gowda, R. Superplastic forming with diffusion bonding of titanium alloys. Mater. Today Proc. 2020, 27, 2909-2913. [CrossRef]

10. Zhao, Z.; Xu, J.; Fu, Y.; Li, Z. An investigation on adaptively machining the leading and tailing edges of an SPF/DB titanium hollow blade using free-form deformation. Chin. J. Aeronaut. 2018, 31, 178-186. [CrossRef]

11. Li, X.; Wang, G.; Zhang, J.; Liu, Y. Electrically assisted superplastic forming/diffusion bonding of the Ti $2 \mathrm{AlNb}$ alloy sheet. Int. J. Adv. Manuf. Technol. 2019, 106, 77-89. [CrossRef] 
12. Wang, K.; Wang, L.; Zheng, K.; He, Z.; Politis, D.J.; Liu, G.; Yuan, S. High-efficiency forming processes for complex thin-walled titanium alloys components: State-of-the-art and perspectives. Int. J. Extreme Manuf. 2020, 2, 032001. [CrossRef]

13. Wu, F.; Chen, W.; Zhao, B.; Hou, H.; Zhou, W.; Li, Z. Diffusion Bonding of 1420 Al-Li Alloy Assisted by Pure Aluminum Foil as Interlayer. Materials 2020, 13, 1103. [CrossRef] [PubMed]

14. Zhang, T.; Sha, H.; Li, L.; Gong, H. Study of Macroscopic Defects of Four-Layer Structure of Ti-6Al-4V During Superplastic Forming/Diffusion Bonding. Int. J. Precis. Eng. Manuf. 2021, 22, 27-39. [CrossRef]

15. Wu, Y.; Wu, D.; Ma, J.; Xiao, W.; Zheng, K.; Chen, M. A physically based constitutive model of Ti-6Al-4V and application in the SPF/DB process for a pyramid lattice sandwich panel. Arch. Civ. Mech. Eng. 2021, 21, 1-17. [CrossRef]

16. Du, Z.; Zhang, K. The superplastic forming/diffusion bonding and mechanical property of TA15 alloy for four-layer hollow structure with squad grid. Int. J. Mater. Form. 2021, 14, 1057-1066. [CrossRef]

17. Du, Z.; Wang, G.; Wang, H. The Process Design and Rapid Superplastic Forming of Industrial AA5083 for a Fender with a Negative Angle in a Small Batch. Metals 2021, 11, 497. [CrossRef]

18. Somekawa, H.; Singh, A. Superior room temperature ductility of magnesium dilute binary alloy via grain boundary sliding. Scr. Mater. 2018, 150, 26-30. [CrossRef]

19. Sherby, O.D.; Wadsworth, J. Superplasticity-Recent advances and future directions. Prog. Mater. Sci. 1989, 33, 169-221. [CrossRef]

20. Okamoto, H. Alloy Phase Diagram. In ASM HANDBOOK; ASM International: Almere, The Netherlands, 1992; Volume 3, p. 747. 